\title{
Syndrome of inappropriate antidiuretic hormone secretion and cerebral/renal salt wasting syndrome: similarities and differences
}

\author{
Ji Young Oh and Jae II Shin* \\ Department of Pediatrics, Severance Children's Hospital, Yonsei University College of Medicine, Seoul, South Korea
}

\section{Edited by:}

Jacqueline Ho, Children's Hospital of Pittsburgh of University of Pittsburgh Medical Center, USA

\section{Reviewed by:}

Jakub Zieg, Charles University in Prague, Czech Republic

Michael L. Moritz, Children's Hospital

of Pittsburgh of University of

Pittsburgh Medical Center, USA

John Maesaka, Winthrop-University

Hospital, USA

\section{*Correspondence:}

Jae II Shin, Department of Pediatrics, Severance Children's Hospital, Yonsei University College of Medicine, 50 Yonsei-ro, Seodaemun-gu, C.P.O. Box 8044, Seoul 120-752, South Korea e-mail: shinji@yuhs.ac
Hyponatremia (sodium levels of $<135 \mathrm{mEq} / \mathrm{L}$ ) is one of the most common electrolyte imbalances in clinical practice, especially in patients with neurologic diseases. Hyponatremia can cause cerebral edema and brain herniation; therefore, prompt diagnosis and proper treatment is important in preventing morbidity and mortality. Among various causes of hyponatremia, diagnosing syndrome of inappropriate antidiuretic hormone secretion (SIADH) and cerebral/renal salt wasting syndrome (C/RSW) is difficult due to many similarities. SIADH is caused by excess of renal water reabsorption through inappropriate antidiuretic hormone secretion, and fluid restriction is the treatment of choice. On the other hand, C/RSW is caused by natriuresis, which is followed by volume depletion and negative sodium balance and replacement of water and sodium is the mainstay of treatment. Determinating volume status in hyponatremic patients is the key point in differential between SIADH and C/RSW. However, in most situations, differential diagnosis of these two diseases is difficult because they overlap in many clinical and laboratory aspects, especially to assess differences in volume status of these patients. Although distinction between the SIADH and C/RSW is difficult, improvement of hypouricemia and an increased fractional excretion of uric acid after the correction of hyponatremia in SIADH, not in C/RSW, may be one of the helpful points in discriminating the two diseases. In this review, we compare these two diseases regarding the pathophysiologic mechanisms, diagnosis, and therapeutic point of view.

Keywords: hyponatremia, syndrome of inappropriate antidiuretic hormone secretion, cerebral/renal salt wasting syndrome, volume status, fractional excretion of urate

\section{INTRODUCTION}

Hyponatremia, defined by sodium levels of $<135 \mathrm{mEq} / \mathrm{L}$, is one of the common electrolyte imbalances in clinical practice, especially among patients with neurologic diseases (1). Prevalence of hyponatremia is approximately $15-30 \%$ in hospitalized patients, both children and adults, and 1-8\% in outpatient clinic setting (2). Acute hypoosmolality caused by serum sodium levels of 110 $120 \mathrm{mEq} / \mathrm{L}$ can cause cerebral edema and herniation (3-5). After this osmotic insult, the adaptation mechanism of losing the electrolytes and organic osmolytes in brain tissue facilitates restoration of the brain volume $(6,7)$. This mechanism is known as "'osmoregulation" $(8,9)$. However, correcting sodium levels too fast for the brain tissue to adapt, especially in patients with more vulnerable brain tissue due to neurologic disorders, can impair this osmoregulatory mechanism (9). Therefore, patients in these situations present brain deterioration that is more serious and have show increased mortality rates $(4,9)$. Thus, rapid diagnosis of hyponatremia is important in preventing morbidity and mortality in patient management, especially in neurologic intensive care settings.

Among various causes of hyponatremia, the diagnoses of the syndrome of inappropriate antidiuretic hormone secretion (SIADH) and cerebral/renal salt wasting syndrome (C/RSW) are still confusing due to many similarities. According to one retrospective study of electrolyte disturbances in 195 children with acute central nervous system (CNS) diseases, 20 (10.3\%) children showed hyponatremia, 7 of them were diagnosed with SIADH, and the other 9 with cerebral salt wasting syndrome (CSW) (1).

Although it may be difficult to distinguish between the two diseases, it is important to do so since the treatment of the two diseases differ in many aspects (10). In this review, we would like to compare these two diseases, which have many differences related to the pathophysiologic mechanisms, diagnosis, and therapeutic points of view despite the similarities.

\section{DEFINITIONS AND PATHOPHYSIOLOGIC MECHANISMS OF SIADH}

SIADH is a disease categorized as hypo-osmolar hyponatremia; small amount of volume expansion is caused by excess of renal water reabsorption through inappropriate antidiuretic hormone (ADH) secretion (11). Before the diagnosis of SIADH, other diseases such as dysfunctions of heart, liver and kidneys, adrenal insufficiency, and hypothyroidism, should be excluded. Excessive ADH secretion causes water retention by increasing water permeability in the renal collecting duct (12). Consequently, the increased glomerular filtration rate (GFR) due to the 
volume expansion and vasodilating effect of increased circulating atrial/brain natriuretic peptides can increase sodium excretion but there is also decreased tubular transport of sodium due to unknown mechanism $(12,13)$. In addition, natriuretic peptides are released primarily due to vasopressin stimulation (14) and, secondarily due to overfilling of the plasma volume by homeostatic mechanisms (15). Increased pressure in the glomerular capillaries and decreased plasma renin and aldosterone secretion can lead to natriuresis by increasing GFR and blocking sodium reabsorption in the collecting duct (14-16).

\section{DEFINITIONS AND PATHOPHYSIOLOGIC MECHANISMS OF C/RSW}

C/RSW is another important disease category causing hyponatremia, characterized by volume depletion and negative sodium balance. Peters et al. first described C/RSW in a report of three patients with neurogenic diseases and hyponatremia (17). Following the original description of SIADH by Schwartz et al. in 1957, the term C/RSW had not been used for 20 years (12). Then, in 1981, Nelson et al. studied hyponatremia in patients undergoing neurosurgery, and re-established interest in C/RSW (18). In that journal, Nelson et al. determined blood volume by gold standard radioisotope dilution methods and demonstrated a large number of neurosurgical patients to be volume depleted with high urinary sodium excretion that were very consistent with salt wasting (18). Although C/RSW has also been considered to be caused by sequential complications of CNS diseases (19-21), some reports show that it could occur in patients without CNS diseases; therefore, it is recently referred to as renal salt wasting (RSW) $(22,23)$. As a result of these studies, we agree with changing CSW to RSW because CSW would not be considered in patients without cerebral disease, the prevalence of which has yet to be determined.

The pathophysiology and mechanisms of C/RSW are not completely understood, nevertheless, there is general agreement that the kidneys are unable to conserve sodium leading to variable degrees of reduction in extracellular volume (ECV) depending the extent of the defect in sodium transport and salt intake. In addition, the patient must also have a normally functioning kidney and hypothalamic-pituitary-adrenal axis in order to be diagnosed as C/RSW (17).

This syndrome could be explained with two main hypotheses $(4,24,25)$ : decreased sympathetic outflow to the kidney and amplification of the circulating natriuretic peptide, particularly brain natriuretic peptide (24-26). Sympathetic tone plays an important role in the kidney in sodium and water absorption at proximal tubules and releasing renin at the juxtaglomerular epithelioid cells $(25,27)$. Therefore, theoretically, renin-aldosterone levels are not increased due to reduced sympathetic tone in the kidney despite the volume depletion in C/RSW patients (16), but reninaldosterone levels have been reported to be high in salt wasting (22). The patient with C/RSW initially loses sodium but eventually reaches a steady state where sodium excretion matches sodium intake, and urinary sodium can be low despite having salt wasting. In addition, increased natriuretic peptides induce natriuresis by increasing GFR and preventing sodium reabsorption in the collecting duct $(28,29)$. Also, natriuretic peptides could inhibit the action of aldosterone, antagonize the arginine vasopressin (AVP) effects and reduce sympathetic outflow $(16,24,26)$. However, Maesaka et al. reported that natriuretic peptides were found to be low in a volume depleted patient with RSW and suggested their contribution to RSW is not supported by their modest effect on sodium and other solute transport in the proximal tubules $(22,23)$.

If $\mathrm{ECV}$ is decreased due to C/RSW, the baroreceptors are triggered and $\mathrm{ADH}$ is secreted to restore intravascular volume. The stimulus for $\mathrm{ADH}$ secretion by the reduced $\mathrm{ECV}$ is more potent than the osmolar effect on $\mathrm{ADH}$ secretion, so the patient remains hyponatremic despite the hypoosmolality. This defines the appropriateness of ADH secretion in C/RSW and why saline can remove the volume stimulus for $\mathrm{ADH}$ secretion and allow the hypoosmolality to inhibit $\mathrm{ADH}$ secretion, increase free water excretion and correct the hyponatremia.

\section{SIADH AND C/RSW: SIMILARITIES AND DIFFERENCES}

Distinguishing between SIADH and C/RSW is important since the proper treatment for each disease is different, and erroneous diagnosis could endanger the patient. However, it is difficult to distinguish the two diseases because many clinical symptoms and laboratory findings overlap. Hyponatremia is a common finding of both SIADH and C/RSW, but the most important difference between the two diseases is the patient's volume status. SIADH tends to be euvolemic or slightly hypervolemic, whereas C/RSW tends to be hypovolemic $(13,24)$. Patients with SIADH do not present overt hypervolemic signs clinically, since one-third of the retention fluid remains in the extracellular space (13). Therefore, it is difficult to distinguish between the two diseases with only clinical symptoms and physical examinations (e.g., edema or neck vein distension), measurements of blood pressure, or pulse rate according to posture change. There have been some methods for the direct estimation of circulating blood volume by central venous catheter (measurement of central venous pressure) or Swan-Ganz catheter (measurement of pulmonary capillary wedge pressure) in patients without cardiac or pulmonary diseases $(4,13,30)$. However, CVP determinations do not accurately determine the volume status of patients when compared to gold standard radioisotope dilution methods, and there is no exact and easily applicable method, which can be used to define volume status in children.

In addition, urine electrolytes can be used to evaluate volume status $(31,32)$. Generally, it is known to be helpful diagnosing SIADH when the patient exhibits urinary sodium and chloride excretion increased more than $30 \mathrm{mmol} / \mathrm{L}$ and fractional excretions of sodium and chloride more than $0.5 \%$ (33). In SIADH patients with water retention, hypertension or catecholamineinduced vasoconstriction can also induce aggressive natriuresis temporarily, and therefore measuring mass balance of urinary electrolytes over a few days may be more helpful to make a decision $(24,34)$. Unfortunately, there is no gold standard cut-off value of urinary sodium excretion to distinguish the two diseases.

Although laboratory findings such as elevated hematocrit, plasma blood urea nitrogen (BUN), or albumin level might reflect low effective blood volume in $\mathrm{C} / \mathrm{RSW}(13,33,35)$, it may be difficult to evaluate volume status accurately. Serum uric acid levels are generally decreased and fractional excretions of uric acid (FEUrate) are increased both in SIADH and C/RSW (12, 33, 36), although the mechanisms are not clear. Normal value of the 
FEUrate in euvolemic patients is about $10 \%$ and is reduced (usually $<5 \%)$ in hypovolemic patients $(37,38)$. In most SIADH and C/RSW patients, the level of FEUrate is more than 10\%. Maesaka et al. noted that hypouricemia and an increased FEUrate improve in SIADH, but not in C/RSW after the correction of hyponatremia $(23,37,39)$. This might be associated with impaired sodiumurate-co-transporter in the proximal tubule itself in C/RSW. The FEUrate is suggested that it could be used in the algorithm to distinguish SIADH from C/RSW $(22,23)$. However, an exact value and pathophysiologic mechanisms of decreased serum uric acid level in pediatric patients remain elusive.

Although not tested in children, one recent report demonstrated that bioimpedance spectroscopy showed a higher level of agreement with clinical body fluid estimation than physical examination in adults with hyponatremia, suggesting that bioimpedance spectroscopy could replace physical examination for estimating body fluid status in hyponatremia (40). Because bioimpedance spectroscopy is also used to measure hydration status in children receiving hemodialysis (41), it would be interesting to study if this method could be useful in determining the volume status in children with hyponatremia in the future. However, special attention should be paid utilization of bioimpedance is most effective when volumes are determined at two time intervals where the changes noted between both points are made.

\section{TREATMENT}

Because hyponatremia is poorly tolerated in patients with C/RSW diseases, and even a small decrease in serum sodium can aggravate vasogenic cerebral edema (42), it should be rapidly recognized and managed promptly. Vasogenic edema is accumulating the proteinrich fluid to the extracellular space resulted from destruction of the blood-brain barrier due to increased vascular permeability (43-46).

Three percent $\mathrm{NaCl}$ should be administered for acute symptomatic hyponatremia. Excessive correction of chronic hyponatremia should be avoided as it can result in osmotic demyelination $(10,47)$. Though it is rare, osmotic demyelination is a serious and fatal complication that can cause aggressive neurologic deficit such as seizure, quadriplegia, coma, and even death $(6,47,48)$.

Simple fluid restriction is recommended for the treatment of hyponatremia in uncomplicated SIADH $(11,49)$. Isotonic saline is not usually effective in increasing serum sodium levels in SIADH, because water will be retained and sodium will be excreted in urine, causing possible aggravation of hyponatremia. Hypertonic saline can increase serum sodium levels, but the response will partially dissipate over time and therefore, oral salt tablets with loop diuretics can be considered as a treatment of hyponatremia caused by SIADH (50). Vasopressin receptor antagonists (vaptans) emerged as a new class of drugs for the treatment of euvolemic and hypervolemic hyponatremia such as SIADH in adults (51). Although there have been scarce studies of data research on the use of vaptans in children $(52,53)$, Jones et al. showed that intravenous conivaptan was effective for increasing serum sodium levels and might be a potential adjuvant to enhance diuresis in children with cardiac disease (52) and Horibata et al. reported oral tolvaptan improved the condition of 6 -year-old boy with the loop diuretic-resistant congestive cardiac failure without hypernatremia, deterioration of vital signs, and significant complications (53). The common side effects of vaptans are thirst and increased urination $(2,54)$. Recently, one case report of over-correction of hyponatremia with development of severe hypernatremia and demyelination with usage of vaptan was published $(2,55)$. In addition, one report was reported that long term usage of tolvaptan was resulted in severe hepatotoxicity in a patient with autosomal dominant polycystic kidney disease (2, $56)$. Some reports suggested contraindications of vaptan $(57,58)$. Vaptan therapy is absolutely contraindicated for patients in hypovolemic hyponatremia, because these patients already experienced loss of water and sodium that exceeded hemodynamic compensation and renal function $(57,58)$. Therefore, safety concerns and clinical trials regarding vaptan use in children with SIADH will be necessary in the future.

The treatment purpose of C/RSW is to restore decreased serum sodium levels and intravascular volume due to natriuresis and diuresis and normal saline is frequently used as an initial fluid (4, $30,59)$. If the patient with salt wasting becomes euvolemic with saline, the hyponatremia should be corrected in a short period of time. If it does not, there should be a question of the accuracy of the diagnosis. At the start of the treatment, it might be safer to use hypertonic saline if the patient has symptomatic hyponatremia and then switch to isotonic saline, which should eliminate the more potent volume stimulus for $\mathrm{ADH}$ secretion. To make strengthen the diagnosis of salt wasting, testing for excretion of diluted urines may be useful. Once euvolemia is achieved, the degree of hyponatremia should be re-evaluated. If serum sodium levels are severely decreased $(<125 \mathrm{mEq} / \mathrm{L})$ or a large volume of intravenous fluids is required to maintain euvolemia, intravenous hypertonic saline can also be used (4). A hypertonic 3\% NaCl infusion can be titrated with a $0.9 \% \mathrm{NaCl}$ infusion to obtain the desired sodium concentration to maintain appropriate serum sodium (44, 60 ), or alternatively, mineralocorticoids can be used to augment both serum sodium concentration and intravascular volume (6164). Oral salt supplementation can be used in a stable patient with CNS disease and C/RSW.

\section{CONCLUSION}

Because SIADH and C/RSW have many similarities, differential diagnosis is very difficult in patients with hyponatremia, especially in those with CNS diseases. Nevertheless, it is also important to distinguish between SIADH and C/RSW since the treatment of them differ in many aspects. Volume status of the patients, though it may be difficult to evaluate in the clinical setting, serum uric acid levels and FEUrate after correcting hyponatremia, and the degree of fractional excretions of sodium may be useful in differentiating between the two diseases. Therefore, further studies regarding pathophysiologic mechanisms of diseases and development of diagnostic tools to determine exact volume status is necessary in the future.

\section{ACKNOWLEDGMENTS}

We would like to express our gratitude to all the reviewers who provided valuable comments to us that clearly improved our review article. 


\section{REFERENCES}

1. Bussmann C, Bast T, Rating D. Hyponatraemia in children with acute CNS disease: SIADH or cerebral salt wasting? Childs Nerv Syst (2001) 17(1-2):58-62.

2. Moritz ML, Ayus JC. Management of hyponatremia in various clinical situations. Curr Treat Options Neurol (2014) 16(9):310. doi:10.1007/s11940-0140310-9

3. Carandang F, Anglemyer A, Longhurst CA, Krishnan G, Alexander SR, Kahana M, et al. Association between maintenance fluid tonicity and hospitalacquired hyponatremia. J Pediatr (2013) 163(6):1646-51. doi:10.1016/j.jpeds. 2013.07.020

4. Yee AH, Burns JD, Wijdicks EF. Cerebral salt wasting: pathophysiology, diagnosis, and treatment. Neurosurg Clin N Am (2010) 21(2):339-52. doi:10.1016/j. nec.2009.10.011

5. Carpenter J, Weinstein S, Myseros J, Vezina G, Bell MJ. Inadvertent hyponatremia leading to acute cerebral edema and early evidence of herniation. Neurocrit Care (2007) 6(3):195-9. doi:10.1007/s12028-007-0032-x

6. Adrogue HJ, Madias NE. Diagnosis and treatment of hyponatremia. Am J Kidney Dis (2014) 126(10 Suppl 1):S1-42. doi:10.1053/j.ajkd.2014.06.001

7. Agrawal V, Agarwal M, Joshi SR, Ghosh AK. Hyponatremia and hypernatremia: disorders of water balance. J Assoc Physicians India (2008) 56:956-64.

8. Tzamaloukas AH, Malhotra D, Rosen BH, Raj DS, Murata GH, Shapiro JI. Principles of management of severe hyponatremia. J Am Heart Assoc (2013) 2(1):e005199. doi:10.1161/jaha.112.005199

9. Kamoi K, Toyama M, Ishibashi M, Yamaji T. Hyponatremia and osmoregulation of vasopressin secretion in patients with intracranial bleeding. J Clin Endocrinol Metab (1995) 80(10):2906-11. doi:10.1210/jcem.80.10.7559873

10. Adrogue HJ, Madias NE. The challenge of hyponatremia. J Am Soc Nephrol (2012) 23(7):1140-8. doi:10.1681/asn.2012020128

11. Frouget T. The syndrome of inappropriate antidiuresis. Rev Med Interne (2012) 33(10):556-66. doi:10.1016/j.revmed.2012.07.005

12. Schwartz WB, Bennett W, Curelop S, Bartter FC. A syndrome of renal sodium loss and hyponatremia probably resulting from inappropriate secretion of antidiuretic hormone. Am J Med (1957) 23(4):529-42. doi:10.1016/0002-9343(57) 90224-3

13. Palmer BF. Hyponatremia in patients with central nervous system disease: SIADH versus CSW. Trends Endocrinol Metab (2003) 14(4):182-7. doi:10.1016/ S1043-2760(03)00048-1

14. Cogan MG. Atrial natriuretic peptide. Kidney Int (1990) 37(4):1148-60. doi:10.1038/ki.1990.98

15. Peri A, Pirozzi N, Parenti G, Festuccia F, Mene P. Hyponatremia and the syndrome of inappropriate secretion of antidiuretic hormone (SIADH). J Endocrinol Invest (2010) 33(9):671-82. doi:10.3275/7290

16. Levin ER, Gardner DG, Samson WK. Natriuretic peptides. N Engl J Med (1998) 339(5):321-8. doi:10.1056/nejm199807303390507

17. Peters JP, Welt LG, Sims EA, Orloff J, Needham J. A salt-wasting syndrome associated with cerebral disease. Trans Assoc Am Physicians (1950) 63:57-64.

18. Nelson PB, Seif SM, Maroon JC, Robinson AG. Hyponatremia in intracranial disease: perhaps not the syndrome of inappropriate secretion of antidiuretic hormone (SIADH). J Neurosurg (1981) 55(6):938-41. doi:10.3171/jns.1981.55. 6.0938

19. Sorkhi H, Salehi Omran MR, Barari Savadkoohi R, Baghdadi F, Nakhjavani $\mathrm{N}$, Bijani A. CSWS versus SIADH as the probable causes of hyponatremia in children with acute CNS disorders. Iran J Child Neurol (2013) 7(3):34-9.

20. Jimenez R, Casado-Flores J, Nieto M, Garcia-Teresa MA. Cerebral salt wasting syndrome in children with acute central nervous system injury. Pediatr Neurol (2006) 35(4):261-3. doi:10.1016/j.pediatrneurol.2006.05.004

21. Hardesty DA, Kilbaugh TJ, Storm PB. Cerebral salt wasting syndrome in postoperative pediatric brain tumor patients. Neurocrit Care (2012) 17(3):382-7. doi:10.1007/s12028-011-9618-4

22. Maesaka JK, Miyawaki N, Palaia T, Fishbane S, Durham JH. Renal salt wasting without cerebral disease: diagnostic value of urate determinations in hyponatremia. Kidney Int (2007) 71(8):822-6. doi:10.1038/sj.ki.5002093

23. Maesaka JK, Imbriano LJ, Ali NM, Ilamathi E. Is it cerebral or renal salt wasting? Kidney Int (2009) 76(9):934-8. doi:10.1038/ki.2009.263

24. Rabinstein AA, Wijdicks EF. Hyponatremia in critically ill neurological patients. Neurologist (2003) 9(6):290-300. doi:10.1097/01.nrl.0000095258.07720.89

25. Kim DK, Joo KW. Hyponatremia in patients with neurologic disorders. Electrolyte Blood Press (2009) 7(2):51-7. doi:10.5049/ebp.2009.7.2.51
26. Steele MK, Gardner DG, Xie PL, Schultz HD. Interactions between ANP and ANG II in regulating blood pressure and sympathetic outflow. Am J Physiol (1991) 260(6 Pt 2):R1145-51.

27. Schweda F, Friis U, Wagner C, Skott O, Kurtz A. Renin release. Physiology (2007) 22:310-9. doi:10.1152/physiol.00024.2007

28. Marin-Grez M, Fleming JT, Steinhausen M. Atrial natriuretic peptide causes preglomerular vasodilatation and post-glomerular vasoconstriction in rat kidney. Nature (1986) 324(6096):473-6. doi:10.1038/324473a0

29. Damaraju SC, Rajshekhar V, Chandy MJ. Validation study of a central venous pressure-based protocol for the management of neurosurgical patients with hyponatremia and natriuresis. Neurosurgery (1997) 40(2):312-6. doi:10.1097/ 00006123-199702000-00015

30. Harrigan MR. Cerebral salt wasting syndrome. Crit Care Clin (2001) 17(1):125-38. doi:10.1016/S0749-0704(05)70155-X

31. Sherman RA, Eisinger RP. The use (and misuse) of urinary sodium and chloride measurements. JAMA (1982) 247(22):3121-4. doi:10.1001/jama.247.22.3121

32. Winter SD. Measurement of urine electrolytes: clinical significance and methods. Crit Rev Clin Lab Sci (1981) 14(3):163-87. doi:10.3109/10408368109105863

33. Decaux G, Musch W. Clinical laboratory evaluation of the syndrome of inappropriate secretion of antidiuretic hormone. Clin J Am Soc Nephrol (2008) 3(4):1175-84. doi:10.2215/cjn.04431007

34. Carlotti AP, Bohn D, Rutka JT, Singh S, Berry WA, Sharman A, et al. A method to estimate urinary electrolyte excretion in patients at risk for developing cerebral salt wasting. J Neurosurg (2001) 95(3):420-4. doi:10.3171/jns.2001.95.3.0420

35. Sterns RH, Silver SM. Cerebral salt wasting versus SIADH: what difference? J Am Soc Nephrol (2008) 19(2):194-6. doi:10.1681/asn.2007101118

36. Schwartz WB, Bennett W, Curelop S, Bartter FC. A syndrome of renal sodium loss and hyponatremia probably resulting from inappropriate secretion of antidiuretic hormone. 1957. J Am Soc Nephrol (2001) 12(12):2860-70.

37. Maesaka JK, Fishbane S. Regulation of renal urate excretion: a critical review. Am J Kidney Dis (1998) 32(6):917-33. doi:10.1016/S0272-6386(98)70067-8

38. Fenske W, Stork S, Koschker AC, Blechschmidt A, Lorenz D, Wortmann S, et al. Value of fractional uric acid excretion in differential diagnosis of hyponatremic patients on diuretics. J Clin Endocrinol Metab (2008) 93(8):2991-7. doi:10.1210/jc.2008-0330

39. Maesaka JK, Gupta S, Fishbane S. Cerebral salt-wasting syndrome: does it exist? Nephron (1999) 82(2):100-9. doi:10.1159/000045384

40. Kim JS, Lee JY, Park H, Han BG, Choi SO, Yang JW. Estimation of body fluid volume by bioimpedance spectroscopy in patients with hyponatremia. Yonsei Med J (2014) 55(2):482-6. doi:10.3349/ymj.2014.55.2.482

41. Fenech M, Maasrani M, Jaffrin MY. Fluid volumes determination by impedance spectroscopy and hematocrit monitoring: application to pediatric hemodialysis. Artif Organs (2001) 25(2):89-98. doi:10.1046/j.1525-1594.2001.025002089.x

42. McJunkin JE, de los Reyes EC, Irazuzta JE, Caceres MJ, Khan RR, Minnich LL, et al. La Crosse encephalitis in children. N Engl J Med (2001) 344(11):801-7. doi:10.1056/nejm200103153441103

43. Suarez JI. Treatment of acute brain edema. Rev Neurol (2001) 32(3):275-81.

44. Moritz ML, Ayus JC. New aspects in the pathogenesis, prevention, and treatment of hyponatremic encephalopathy in children. Pediatr Nephrol (2010) 25(7):1225-38. doi:10.1007/s00467-009-1323-6

45. Boulard G, Marguinaud E, Sesay M. Osmotic cerebral oedema: the role of plasma osmolarity and blood brain barrier. Ann Fr Anesth Reanim (2003) 22(3):215-9. doi:10.1016/S0750-7658(03)00009-1

46. Olson JE, Banks M, Dimlich RV, Evers J. Blood-brain barrier water permeability and brain osmolyte content during edema development. Acad Emerg Med (1997) 4(7):662-73. doi:10.1111/j.1553-2712.1997.tb03757.x

47. King JD, Rosner MH. Osmotic demyelination syndrome. Am J Med Sci (2010) 339(6):561-7. doi:10.1097/MAJ.0b013e3181d3cd78

48. Adrogue HJ, Madias NE. Hyponatremia. N Engl J Med (2000) 342(21):1581-9. doi:10.1056/nejm200005253422107

49. Esposito P, Piotti G, Bianzina S, Malul Y, Dal Canton A. The syndrome of inappropriate antidiuresis: pathophysiology, clinical management and new therapeutic options. Nephron Clin Pract (2011) 119(1):c62-73. doi:10.1159/ 000324653

50. Pillai BP, Unnikrishnan AG, Pavithran PV. Syndrome of inappropriate antidiuretic hormone secretion: revisiting a classical endocrine disorder. Indian J Endocrinol Metab (2011) 15(Suppl 3):S208-15. doi:10.4103/2230-8210. 84870 
51. Decaux G. SIADH and vaptans. Ann Endocrinol (2012) 73(2):130-4. doi:10. 1016/j.ando.2012.04.005

52. Jones RC, Rajasekaran S, Rayburn M, Tobias JD, Kelsey RM, Wetzel GT, et al. Initial experience with conivaptan use in critically ill infants with cardiac disease. J Pediatr Pharmacol Ther (2012) 17(1):78-83. doi:10.5863/1551-677617.1.78

53. Horibata Y, Murakami T, Niwa K. Effect of the oral vasopressin receptor antagonist tolvaptan on congestive cardiac failure in a child with restrictive cardiomyopathy. Cardiol Young (2014) 24(1):155-7. doi:10.1017/ s1047951112002272

54. Konstam MA, Gheorghiade M, Burnett JC Jr., Grinfeld L, Maggioni AP, Swedberg $\mathrm{K}$, et al. Effects of oral tolvaptan in patients hospitalized for worsening heart failure: the EVEREST Outcome Trial. JAMA (2007) 297(12):1319-31. doi:10.1001/jama.297.12.1319

55. Malhotra I, Gopinath S, Janga KC, Greenberg S, Sharma SK, Tarkovsky R. Unpredictable nature of tolvaptan in treatment of hypervolemic hyponatremia: case review on role of vaptans. Case Rep Endocrinol (2014) 2014:807054. doi:10.1155/2014/807054

56. Torres VE, Chapman AB, Devuyst O, Gansevoort RT, Grantham JJ, Higashihara E, et al. Tolvaptan in patients with autosomal dominant polycystic kidney disease. N Engl J Med (2012) 367(25):2407-18. doi:10.1056/NEJMoa1205511

57. Robertson GL. Vaptans for the treatment of hyponatremia. Nat Rev Endocrinol (2011) 7(3):151-61. doi:10.1038/nrendo.2010.229

58. Aditya S, Rattan A. Vaptans: A new option in the management of hyponatremia. Int J Appl Basic Med Res (2012) 2(2):77-83. doi:10.4103/2229-516x.106347

59. Yamaki T, Tano-oka A, Takahashi A, Imaizumi T, Suetake K, Hashi K. Cerebral salt wasting syndrome distinct from the syndrome of inappropriate secretion of antidiuretic hormone (SIADH). Acta Neurochir (1992) 115(3-4):156-62. doi:10.1007/BF01406376

60. Moritz ML. Syndrome of inappropriate antidiuresis and cerebral salt wasting syndrome: are they different and does it matter? Pediatr Nephrol (2012) 27(5):689-93. doi:10.1007/s00467-012-2112-1
61. Wijdicks EF, Vermeulen M, van Brummelen P, van Gijn J. The effect of fludrocortisone acetate on plasma volume and natriuresis in patients with aneurysmal subarachnoid hemorrhage. Clin Neurol Neurosurg (1988) 90(3):209-14. doi:10. 1016/0303-8467(88)90023-6

62. Mori T, Katayama Y, Kawamata T, Hirayama T. Improved efficiency of hypervolemic therapy with inhibition of natriuresis by fludrocortisone in patients with aneurysmal subarachnoid hemorrhage. J Neurosurg (1999) 91(6):947-52. doi:10.3171/jns.1999.91.6.0947

63. Kinik ST, Kandemir N, Baykan A, Akalan N, Yordam N. Fludrocortisone treatment in a child with severe cerebral salt wasting. Pediatr Neurosurg (2001) 35(4):216-9. doi:10.1159/000050424

64. Choi MJ, Oh YS, Park SJ, Kim JH, Shin JI. Cerebral salt wasting treated with fludrocortisone in a 17-year-old boy. Yonsei Med J (2012) 53(4):859-62. doi:10.3349/ymj.2012.53.4.859

Conflict of Interest Statement: The authors declare that the research was conducted in the absence of any commercial or financial relationships that could be construed as a potential conflict of interest.

Received: 08 June 2014; accepted: 23 December 2014; published online: 22 January 2015.

Citation: Oh JY and Shin JI (2015) Syndrome of inappropriate antidiuretic hormone secretion and cerebral/renal salt wasting syndrome: similarities and differences. Front. Pediatr. 2:146. doi: 10.3389/fped.2014.00146

This article was submitted to Pediatric Nephrology, a section of the journal Frontiers in Pediatrics.

Copyright (C) 2015 Oh and Shin. This is an open-access article distributed under the terms of the Creative Commons Attribution License (CC BY). The use, distribution or reproduction in other forums is permitted, provided the original author(s) or licensor are credited and that the original publication in this journal is cited, in accordance with accepted academic practice. No use, distribution or reproduction is permitted which does not comply with these terms. 